\title{
Taxonomic Notes on Channa Species Collected from Thiruvalla, Kerala
}

\section{Dr. Mathews Plamoottil}

Asst. Professor in Zoology, Baby John Memorial Govt. College, Chavara, Kollam Dt, Kerala, India

Abstract: Taxonomic studies conducted on five Channa species collected from some low level regions of central Travancore. Their morphometric features, meristic counts and metric characters are analyzed.

Keywords: Travancore, Biodiversity, Taxonomy, Percoid fishes, Ophiocephalus

\section{INTRODUCTION}

Channa species are a group of percoid fishes having wide natural distribution in various parts of south East Asian countries. They are extensively cultured in India, Thailand and Myanmar. 34 species of snakeheads are now considered as distinct species. Channa species are characterized by the presence of wide mouth and gill openings, plate like scales on head, elongated swim bladder and interrupted lateral line. They are also remarkable in the absence of pseudobranchiae $[1,2]$.

Even though many studies had been conducted in past, relevant systematic studies on snakeheads are rare. A few new Channa species has been described recently; but many of the previous scientific names of the species of this genus are considered as synonyms of other common available species. Thus taxonomy and phylogeny of the Channid fishes remains as a complex and unresolved problem. Vishwanath \& Geethakumari [3] conducted taxonomic studies on the Channa species of northeastern India; they included Channa species under Marulius group and Gachua group with distinct anatomical differences. No serious attention was given on the taxonomy of Channa species of Kerala. It is an endeavor to study systematic details of some Channa species collected from Thiruvalla.

\section{MATERIALS AND MeThODS}

\subsection{Study Sites}

The Study was conducted during the period from January 2010 to December 2012. Manackachira, Kuttoor, Kallumkal and West Venpala are the sites selected for fish collection. These low level regions are characterized by fairly thick riparian vegetation. These areas are floored by means of sand dominated sediments.

\subsection{Fish Collection and Preservation}

Gill nets and Caste nets were used for fish collection; nine percent formalin was used as preservative.

\subsection{Identification}

Methods used are of Jayaram $[4,5]$ and measurements followed standard practices. Taxonomic identification is based mainly on meristic, morphometric and descriptive characters. Relevant measurements were taken and they were worked out as percentage of head length or standard length.

\subsection{Abbreviations Used}

HW-head width; HD-head depth; BDD-body depth at dorsal fin origin; BWD-body width at dorsal fin origin; BDMA-body depth at middle of anal fin; BWMA-body width at middle of anal fin; PRD-pre dorsal distance; PRA- pre anal distance; PRP- pre pectoral distance; PRPL- pre pelvic distance; LPlength of pectoral fin; LPL-length of pelvic fin; LA-length of anal fin; LC- length of caudal fin; LBDlength of base of dorsal fin; LBA- length of base of anal fin; LBC-length of base of caudal fin; DVVdistance from ventral to vent; IOW-interorbital distance; INW-internarial width; ED- eye diameter; STL-snout length; WGM-width of gape of mouth. 


\section{RESULTS AND DISCUSSION}

Five different Channa species were collected during this study (Fig. 1- 6) . Detailed taxonomic studies were conducted on it.

\subsection{Channa gachua (Hamilton- Buchanan)}

Ophiocephalus gachua Hamilton- Buchanan [6], Fishes of Ganges: 68, 367, (type locality: Bengal).

Common name: Asiatic snakehead

Regional Names: Manathukannan, Cheran Koravu, Vattudi, Vattakkannan, Vatton

Synonyms: Ophiocephalus gachua O. apus, O. gachua kelaarti, O. harcourt- butleri, Channa burmanica

Habitat: Paddy fields, ponds, rivers, and streams.

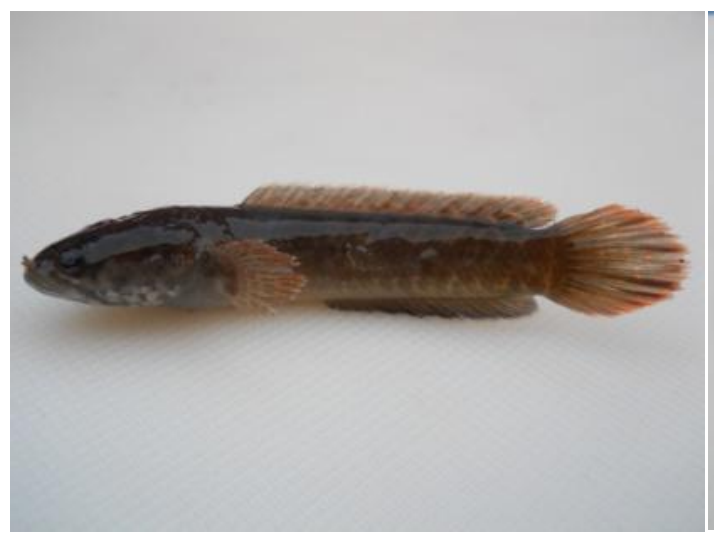

Fig.1. Channa gachua, freshly collected

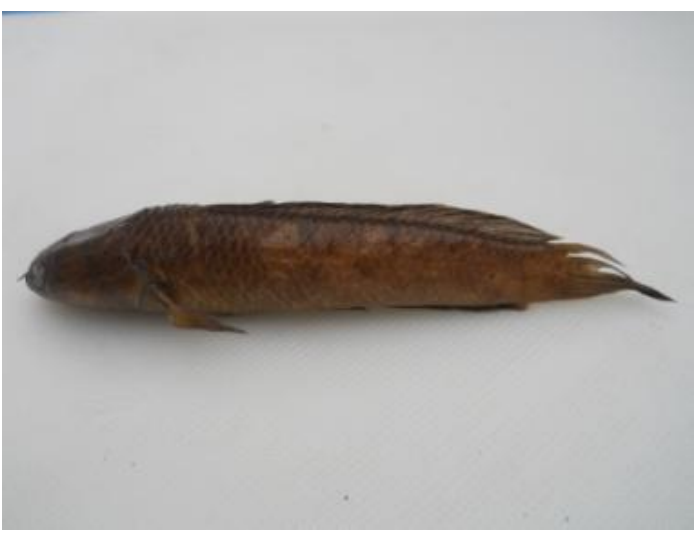

Fig. 2. Channa orientalis, Preserved

Diagnosis: Forty scales present in longitudinal series; twelve scales present before the dorsal fin; a black ocellus is present at the end of dorsal fin.

Meristic counts: P- 13; D- 28; V- 5; A- 19; C- 11; PDS- 12; LLS- 40; LL/D- $31 \frac{1}{2}$; LL/V- 5 11/2; LL/A$5 \frac{1}{2}$.

Metric characters: TL (mm) - 77.0; SL (mm)- 62.0; \% SL: HL- 32.3; HW-22.6; HD- 19.4; BDD17.7; BWD- 14.5; BDMA-14.5; BWMA- 11.3; PRD-40.3; PRA- 58.1; PRP-42.0; PRPL- 40.3; LP19.4; LPL-96.8; LA- 4.8; LC-24.2; LBD-56.5; LBA-38.7; LBC-12.9; DVV- 17.7; \% HL: IOW-30.0; INW-25.0;.ED-15.0; STL-25.0; WGM- 40.0; HD- 60.0; HW-70.0;

Other features: Anterior nostrils in the form of elongated tubes. Pectoral fin with a series of distinct alternating blue and orange crescent bands; dorsal and anal fin elongated; tip of posterior ray of dorsal fin reach the base of caudal; anteriorly it reach just behind the origin of pectoral; some short oblique bands present on the dorso- lateral and ventro- lateral sides of the body; outer margin of caudal fin bright orange and barred.

These were the common species of snake heads of Kerala ${ }^{3,4}$; but now their number has been reduced in many localities.

Distribution: Sri Lanka, India, Pakistan, Iran, Afghanistan, East Indies, Myanmar.

Economic Importance: Inedible; used as bait for catching large fishes such as freshwater sharks.

\subsection{Channa orientalis Bloch \& Schneider}

Channa orientalis Bloch \& Schneider, Syst. Ichth: 496, pl.90 (Type locality: India).

Regional names: Manathukannan, vatton, koravu, vattudi

Common name: Ceylon snakehead, Asiatic snakehead

Synonyms: Ophiocephalus aurantiacus, O. apus, O. marginatus

Habitat: Streams, ponds, branches of rivers

Diagnosis: Six scales present before dorsal fin; eight rays in pelvic fin. 
Meristic counts: D- 26; P- 13; V- 8; A- 21; C- 11; LLS- 38; PDS- 6; LL/D- 4 11/2; LL/V- 7 1/2; LL/A- 7 $1 / 2$.

Metric characters: TL (mm) - 156.0; SL (mm)- 126.5; \% SL: HL- 34.0; HD-18.6; HW- 19.8; BDD25.0; PRD-38.0; PRP- 34.4; LD- 10.7; LBD- 56.1; LBA-37.6; LP- 17.8; LPL- 14.6; LA- 10.7; LC23.3; LCP- 6.6; DCP-11.2. \% HL: HD-54.7; ED- 18.6; STL- 18.6; IOW- 20.9; INW- 22.1; WGM25.6 .

Distribution: India, Sri Lanka, Afghanistan, Myanmar, East Indies Iran, Pakistan, Nepal and Bangladesh;.

Economic Importance: Inedible; no importance in fisheries.

\subsection{Channa marulius (Hamilton- Buchanan)}

Ophiocephalus marulius Hamilton- Buchanan [6], Fishes of Ganges: 65, 367 (type locality: Gangetic provinces).

Common Name: Giant Snake head

Regional Names: Cherumeen, Cheruvaral

Synonyms: Ophiocephalus marulius, O. pseudomarulius, O. lecopunctatus, C. marulius ara.

Habitat: Rivers, lakes, large ponds

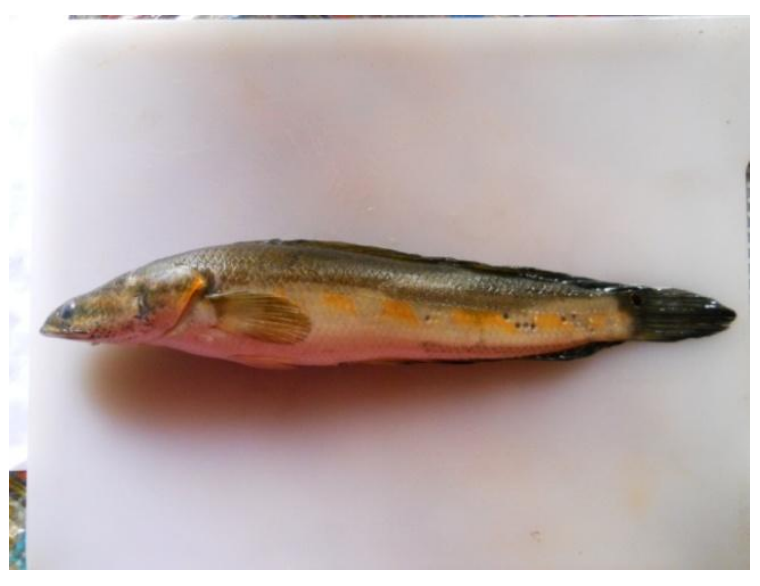

Fig. 3. Channa marulius, Freshly collected

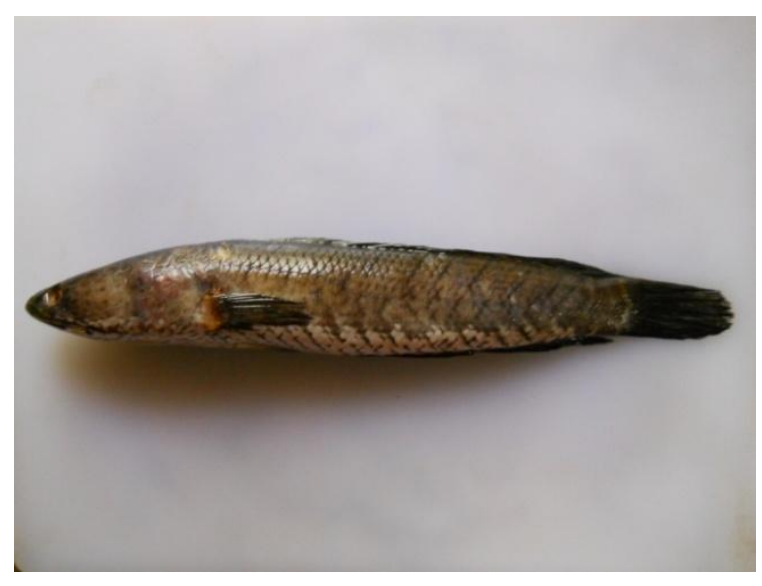

Fig. 4. Channa striatus, preserved

Diagnosis: Large black blotches adorn the sides of the long body. Sixty six scales present on the lateral sides of the body. Sixteen scales present before the dorsal fin. A black white edged ocellus present on upper part of basal portion of caudal fin.

Meristic counts: D- 49; P- 18; V-7; A- 32; C- 14; LLS- 66.

Metric characters: TL (mm) - 24.0; SL (mm) - 20.0. \% SL: HL- 32.5; HD-25.6; BDD-16.5; PRD34.4; POD-64.4; PRP-36.7; LD- 8.9; LBD-64.4; LBA-33.3; LP-16.7; LPL-12.2; LCP-8.0; DCP-10.6.

Other features: White spots are scattered over the body; fins are mottled with white spots.

Distribution: Sri Lanka, India, Pakistan, Nepal, Burma, Bangadesh, Thailand, China

Economic Importance: It is a valuable food fish. Cultured in various ponds in Kerala.

\subsection{Channa striatus (Bloch)}

Ophiocephalus striatus Bloch [8], Natures. Ausland. Fische, (7): 141 (type locality: Malabar).

Common Name: Striped snakehead, banded snake head

Regional Name: Varal, sadharana viral, bral, sowrah

Synonym: Ophiocephalus striatus

Habitat: Streams and ponds

Diagnosis: Seventeen scales present before dorsal fin; lateral line scales 56. Dark oblique bands pass from ventral surface up to the lateral line; caudal fin with two distinct vertical bands at its base. 
Meristic counts: D- 44; P- 15; V- 6; A- 25; C- 13; LLS- 56; LL/D- 4 1/2; LL/V- 7 1/2; PDS-17; LL/A11; PRPS- 6; PRPLS- 10; PRAS- 25; CPS- 10.

Metric characters: TL (mm) - 220.0; SL (mm)- 180.0; \% SL: HL- 34.4; HD-25.6; BDD- 25.0; PRD34.4; POD-64.4; PRP-36.7; LD- 8.9; LBD-64.4; LBA-33.3; LP-16.7; LPL-12.2; LCP-7.2; DCP-10.6. \% HL: HD-74.2; ED- 13.0; STL-16.1.

Other features: Belly pure white; fins spotted; dorsal and anal fins have a dark stain; head elongated; mouth superior; jaws sub equal; lateral line curves downward in the 12th scale.

Remarks: Channa striatus is a widely distributed species of snakehead; specimens collected from various localities showed considerable color differences.

Distribution: Sri Lanka, India, Pakistan, Nepal, Bangladesh, Thailand, Burma, China

Economic Importance: Highly valued as food; cultivated in India and neighboring countries.

\subsection{Channa diplogramma (Day)}

Ophiocephalus diplogramma Day [7], The fishes of Malabar, 147- 148

Common Name: Malabar snakehead

Regional Name: Vaaaka, Vaaka viral

Synonyms: Ophiocephalus diplogramma, O. diplogramma Day; O. diplogramme Day; O. micropeltes non Cuvier; Channa micropeltes (non Cuvier)

Habitat: Larger Rivers

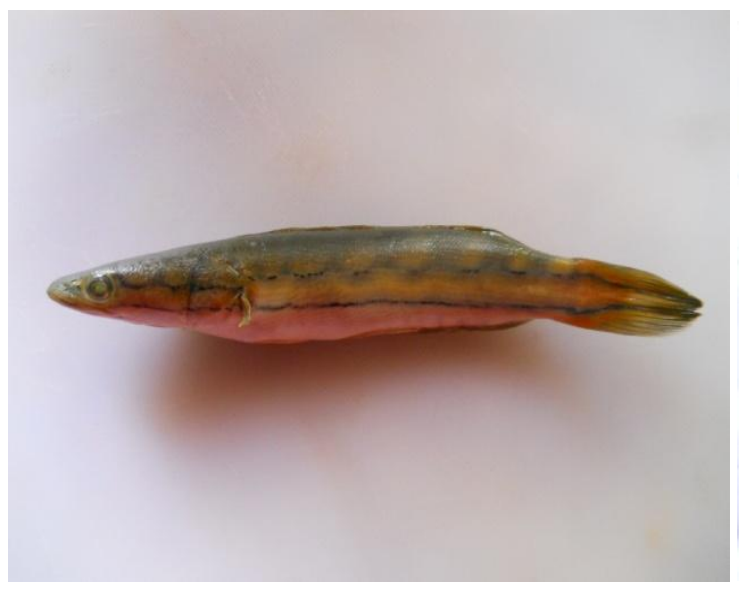

Fig. 5. Channa diplogramma, Young Adult

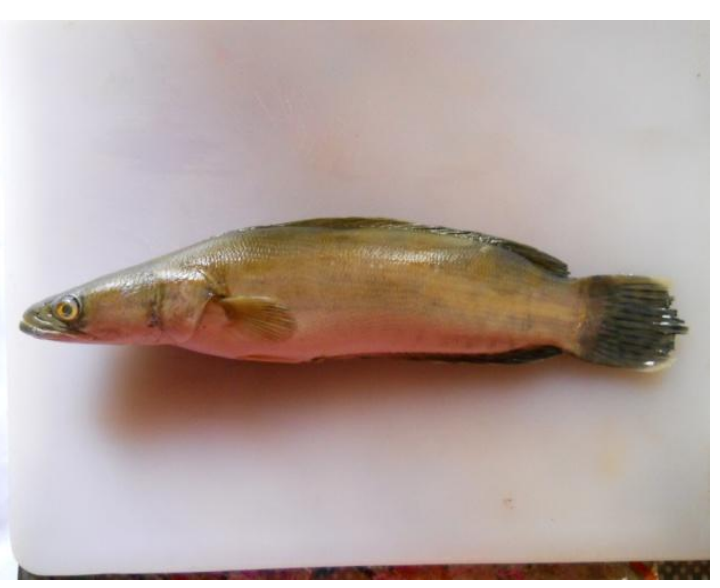

Fig.6. Channa diplogramma, Adult

Diagnosis: Dorsal fin with 42 and anal fin with 25 rays; lateral line scales 102; minute brownish spots present on body.

Meristic counts: D- 41;- 44; V- I, 5; P- 14- 15; A- 25; C- 14; LLS- 102- 112; $\quad$ LR/V- 6-7/16-18; PDS- 22; CPS- 15.

Metric Characters: TL (mm)- 235.0; SL (mm)-193.0; HL (mm) - 66.0. \% SL: HL-34.2; HD-16.6; HW- 17.9; BDD-16.6; BDA- 19.8; PRD-27.5; POD-69.0; PRP-36.8; PRPL- 33.2; LD-7.3; LP-12.0; LPL-10.8; LBD-62.2; LBA-36.8; LCP-10.4; DCP-10.4; WCP- 4.8; \% HL: HD-48.5; ED-12.1; STL22.7.

Other features: Dorsal and dorso lateral sides are greenish dark; ventral and ventro lateral sides yellowish; dorsal and caudal fins with a light dark color; pectoral and pelvic fin yellowish; eyes are protruding.

Remarks: Young adults are morphologically different to fully grown adults; in young ones 2 black horizontal stripes run from the tip of head to caudal tip; Benziger et al. of Kerala redescribed $C$. diplogramma based on their collections from central Travancore. Distribution: India (Kerala \& TamilNadu)

Economic Importance: As its number is less, minor interest to fisheries 


\section{Conclusion}

Taxonomic details of many Channa species are poorly understood; different variants of Channa gachua and Channa marulius are abundant in Kerala; they must be taxonomically analyzed. Channa micropeltes found in Kerala must also be compared with its congeners from type locality. Chaana orientalis also appear in different forms and colors; taxonomy of Channa gachua and C. orientalis remains as a complex and unresolved problem even now. It can only be solved using biotechnological methods. Ophiocephalus marginatus will most probably be a distinct species; it may reside in the water bodies of northern Kerala and neighboring states. More relevant taxonomic studies alone will solve the ambiguities existing in the various species of Channa.

\section{ACKNOWLEDGEMENTS}

I am greatly indebted to Principal, Government College, Chavara, for providing necessary facilities

\section{REFERENCES}

[1] Talwar PK. \& Jhingran, A. Inland fishes of India and adjacent countries, Oxford and IBH publishing Co. Pvt. Ltd. 1991, 234.

[2] Jayaram KC. Fresh water fishes of the Indian region, Narendra publishing House, Delhi, 2010, 256- 260.

[3] Vishwanath W. \& Geetakumari, KH. Diagnosis and interrelationships of fishes of the genus Channa Scopoli (Teleostei: Channidae) of northeastern India. Journal of Threatened Taxa, 2009, 1(2): 97-105.

[4] Jayaram KC. Fresh water fishes of the Indian region. Narendra publishing House, Delhi. 1999.

[5] Jayaram KC. Fundamentals of fish taxonomy, Narendra publishing House, Delhi. 2002. 174.

[6] Hamilton F. An Account of Fishes found in the River Ganges and its branches. Archibald Constable, Edinburgh and Hurst, Robinson, London, pp. 1822.405

[7] Day, F. 1965. The fishes of Malabar. Bernad Quritch, London, 1865, 185.

[8] Bloch ME. Naturegeschichte der auslandischen fische, Berlin. 9, Parts in 2 and atlas (3 vols.). Edinburgh Hurst, Robinson \& Co, London, 1785- 1795, 312-389. 